\title{
Glyceryl trinitrate-induced cytotoxicity of docetaxel-resistant prostatic cancer cells is associated with differential regulation of clusterin
}

\author{
SARRA BOUAOUICHE ${ }^{1,2^{*}}$, LEA MAGADOUX ${ }^{1,2^{*}}$, LUCILE DONDAINE $^{1,2}$, SYLVIE REVENEAU $^{1,2}$, \\ NICOLAS ISAMBERT $^{3}$, ALI BETTAIEB ${ }^{1,2}$, JEAN-FRANÇOIS JEANNIN ${ }^{1,2}$, \\ VERONIQUE LAURENS ${ }^{1,2^{* *}}$ and STEPHANIE PLENCHETTE ${ }^{1,2^{* *}}$ \\ ${ }^{1}$ Laboratoire d'Immunologie et Immunothérapie des Cancers, EPHE, PSL Research University, F-75000 Paris; \\ ${ }^{2}$ LIIC, EA7269, Université de Bourgogne Franche-Comté; ${ }^{3}$ Centre Georges-François Leclerc, F-21000 Dijon, France
}

Received September 11, 2018; Accepted December 21, 2018

DOI: 10.3892/ijo.2019.4708

\begin{abstract}
Metastatic castration resistant prostate cancer (mCRPC) relapse due to acquired resistance to chemotherapy, such as docetaxel, remains a major threat to patient survival. Resistance of mCRPC to docetaxel can be associated with elevated levels of soluble clusterin (sCLU) and growth differentiation factor-15 (GDF-15). Any strategies aiming to modulate sCLU and/or GDF-15 in docetaxel-resistant prostate cancer cells present a therapeutic interest. The present study reports the cytotoxic effect of a nitric oxide donor, glyceryl trinitrate (GTN), on docetaxel-resistant mCRPC human cell lines and demonstrates that GTN displays greater inhibition of cell viability toward docetaxel-resistant mCRPC cells than on mCRPC cells. It is also demonstrated that GTN modulates the level of expression of clusterin (CLU) which is dependent of GDF-15, two markers associated with docetaxel resistance in prostate cancer. The results indicate that GTN represses the level of expression of the cytoprotective isoform of CLU (sCLU) and can increase the level of expression of the cytotoxic isoform (nuclear CLU) in docetaxel resistant cells. Furthermore, it was observed that GTN differentially regulates the level of the precursor form of GDF-15 between resistant and parental cells, and that recombinant GDF-15 can modulate the expression of CLU isoforms and counteract GTN-induced cytotoxicity in resistant cells. A link was established between GDF-15 and the expression of CLU isoforms. The present
\end{abstract}

Correspondence to: Dr Véronique Laurens or Dr Stéphanie Plenchette, Laboratoire d'Immunologie et Immunothérapie des Cancers (LIIC), Faculté de Médecine, 7 Boulevard Jeanne d'Arc, BP 87900, F-21000 Dijon, France

E-mail: veronique.laurens@u-bourgogne.fr

E-mail: stephanie.plenchette@u-bourgogne.fr

**** Contributed equally

Key words: cancer, prostate, docetaxel, resistance, nitric oxide, clusterin, growth differentiation factor- 15 study thus revealed GTN as a potential therapeutic strategy to overcome docetaxel-resistant mCRPC.

\section{Introduction}

Prostate cancer is the second most commonly diagnosed cancer in men worldwide and the fifth leading cause of cancer mortality (1). Currently, radical prostatectomy and radiotherapy represent 'salvage therapies' for individuals with localized disease. Unfortunately, treatment options for men with metastatic prostate cancer are not curative. While hormone therapy i.e. androgen deprivation therapy reduces tumor progression, relapse frequently occurs following surgical or chemical castration. Over a decade, docetaxel is the first-line systemic chemotherapy used for metastatic castration-resistant prostate cancer (mCRPC) (2).

Docetaxel is a taxane chemotherapeutic agent that sensitizes cancer cells to apoptosis by binding to $\beta$-tubulin and prevents its depolarization blocking cells in the $\mathrm{G} 2 / \mathrm{M}$ phase of the cell cycle (3). By stabilizing the microtubules, docetaxel can inhibit a key driver of mCRPC, androgen receptors signaling $(4,5)$. Although docetaxel demonstrated overall survival benefit, the majority of $\mathrm{mCRPC}$ patients eventually become refractory to this chemotherapy and carries a poor prognosis (6).

A number of previous studies have shed light into the underlying mechanisms that mediate acquired resistance to docetaxel (6-10). Notably, clusterin (CLU), an important stress-induced chaperone (when overexpressed), is one characterized way that confers docetaxel resistance in mCRPC (11). CLU, also known as Apolipoprotein $\mathrm{J}$, is an ATP-independent glycoprotein present in all human tissues and fluids (12). It exists in at least two forms with different subcellular localization and antagonistic functions: The soluble clusterin (sCLU) and the nuclear clusterin (nCLU) form, reported to serve distinct roles in cancer, protumoral and antitumoral, respectively (13). The sCLU is the most predominant form. It is a heterodimeric protein comprising two subunits ( $\alpha$ and $\beta$ ) of $\sim 40 \mathrm{kDa}$ each. This form bears endoplasmic reticulum signal peptide sequence that directs the protein to the endoplasmic reticulum and then to the Golgi apparatus where it undergoes 
various post translational modifications during maturation. The mature protein $(80 \mathrm{kDa})$ is then cleaved by a furin-like convertase to produce the two subunits (14). Elevated levels of sCLU support a cytoprotective role through the inhibition of pro-apoptotic signaling pathways, in cells challenged with different therapeutic agents allowing them to mediate resistance to treatment induced-apoptosis $(15,16)$. Several preclinical studies have been performed investigating the inhibition of the level of CLU and have exhibited enhanced chemosensitivity of human prostate cancer cells to treatment-induced apoptosis and delay tumor progression $(17,18)$. This has led to the clinical development of OGX-011 (custirsen), a second-generation antisense oligonucleotide inhibitor of CLU $(19,20)$. The results of two phase II studies of custirsen in combination with docetaxel or second-line chemotherapy in men with mCRPC reported reduced CLU expression within tumor cells, as well as lowered serum CLU levels which are correlated with improved survival (21-23).

An alternative splicing of CLU mRNA generates nCLU (55 kDa) that lacks the endoplasmatic reticulum signal peptide sequence and localizes in the nucleus. In contrast, the cytotoxic activity of nCLU in prostate cancer cells is acknowledged. Evidence for an antitumoral role of nCLU is demonstrated through the promotion of cell cycle arrest and antimetastatic activity in prostate cancer cells by decreasing their motility and progression $(24,25)$. Besides sCLU and nCLU, other intracellular non-secreted CLU isoforms are expressed within stressed cells but at a very low level (26).

Cytokines, including growth differentiation factor- 15 (GDF-15), a member of the transforming growth factor (TGF) superfamily, have been reported to be substantially induced in prostate cancer cells exposed to docetaxel and mitoxanthrone chemotherapy and to contribute to tumor cell therapy resistance (27,28). Increased serum GDF-15 levels following one cycle of docetaxel regimen was associated with a shorter overall survival suggesting that GDF-15 could predict for early docetaxel resistance (28). Notably, GDF-15 has been reported to exert also a proapoptotic function in prostate cancer cells (29).

There are now novel therapeutic agents approved in the treatment of mCRPC following docetaxel failure, including cabazitaxel, a second-generation of taxane (30). Nevertheless, there is a growing interest in developing novel therapeutic approaches to overcome resistance to docetaxel and to provide better disease control in mCRPC. Previous preclinical studies have demonstrated the efficacy of nitric oxide (NO) donor therapy for the treatment of prostate cancer $(31,32)$. Many NO donors have been demonstrated to be potent chemosensitiser and/or radiosensitiser against a wide variety of human tumor cells (33-36). It is now well documented that NO exerts dual activities in cancer: Protumoral or antitumoral. NO donors-induced anti-tumoral activities in prostate cancer cells are due to their ability to simultaneously inhibit cell survival, cell growth pathways and sensitize tumor cells to apoptosis. In prostate cancer cells, apoptosis can be positively regulated by NO through the S-nitrosylation and inhibition of nuclear factor-kappa $\mathrm{B}(\mathrm{NF}-\kappa \mathrm{B})$ and subsequent regulated resistant factors such as Yin Yang 1 (YY1) and B cell lymphoma-2 (BCL2)/BCL-extra large (BCL-XL) (32). In addition, a direct role for $\mathrm{NO}$ with the S-nitrosylation of YY1 has been evidenced in reversing tumor necrosis factor-related apoptosis-inducing ligand-resistant prostate cancer cells (37). Furthermore, the therapeutic efficacy of NO donors in the inhibition of epithelial-to-mesenchymal transition phenotype and metastasis has been demonstrated in metastatic human prostatic cancer cells $(38,39)$.

In this present study the sensitivity of docetaxel-resistant human prostate cancer cells to the NO donor glyceryl trinitrate $(\mathrm{GTN})$ and the regulation of resistant markers were examined to explore novel therapeutic strategies for targeting mCRPC.

\section{Materials and methods}

Cell culture. The human mCRPC cell line DU145 was obtained from the American Type Culture Collection (Manassas, VA, USA). The PC3 AG and docetaxel-resistant derivative PC3-D12 cell lines werekindly provided by ProfessorB. Watson(University College Dublin, Dublin, Ireland) (40). The docetaxel-resistant DU145 (DU145-DR) cell line was established within the team. The DU145 parental cells were seeded in T25 flasks ( $2 \times 10^{6}$ cells) and treated twice a week with increasing doses (0.01, 0.1, 0.5, 0.75, 1, 5 and $10 \mathrm{nM}$ ) of docetaxel (Sanofi S.A., Paris, France). Doses were increased at intervals of 2-3 weeks, dependent on the rate of cell proliferation. Following each step, when the cells stopped proliferating and exhibited a modified morphology, as observed via microscopy, docetaxel treatment was ceased immediately and the cells were placed in complete medium. All cells were cultured in Dulbecco's modified Eagle's medium (DMEM)-4.5 g/l glucose supplemented with $10 \%$ fetal calf serum (FCS) (both from Dominique Dutscher SAS, Brumath, France) at $37^{\circ} \mathrm{C}$ in a humid atmosphere of $5 \% \mathrm{CO}_{2}$. All cell lines were mycoplasma free.

Viabilitytest. Cells were seeded in 96-well plates (2,000 cells/well) in complete DMEM medium (100 $\mu \mathrm{l} /$ well). Following $24 \mathrm{~h}$, the DMEM medium was replaced with Opti-MEM ${ }^{\mathrm{TM}}$ medium (Gibco; Thermo Fisher Scientific, Inc., Waltham, MA, USA) for DU145 lines and Opti-MEM ${ }^{\mathrm{TM}}$ supplemented with 1\% FCS for PC3 cell lines. The cells were treated with docetaxel $(0.1$, $0.2,0.4,0.8,1.6,3.2,6.4,12.8,25.6,51.2,102.4,204.8,409.6$ or $819.2 \mathrm{nM})$ or GTN $(25,50,100,200$ or $400 \mu \mathrm{M}$; Merck KGaA, Darmstadt, Germany) supplemented or not with $5 \mathrm{ng} / \mathrm{ml}$ of human recombinant GDF-15 (R\&D Systems, Inc., Minneapolis, MN, USA). Following $72 \mathrm{~h}$ of treatment, cell viability was evaluated by adding MTS (Promega Corporation, Madison, WI, USA). Absorbance (abs) was read following $4 \mathrm{~h}$ at $490 \mathrm{~nm}$. The following formula was used to obtain the percentage of cell viability: $\%$ viable cells $=\left[\left(\mathrm{abs}_{\text {sample }}-\mathrm{abs}_{\text {blank }}\right) /\left(\mathrm{abs}_{\text {control }}-\mathrm{abs}_{\text {blank }}\right)\right] \mathrm{x100}$. Half maximal inhibitory concentration $\left(\mathrm{IC}_{50}\right)$ calculations were determined using GraphPad Prism 6 software (GraphPad Software, Inc., La Jolla, CA, USA).

Cell transfection. Cells were seeded in 6-well plates (DU145 and DU145-DR at $3 \times 10^{5}$ cells/well; PC3 AG and PC3-D12 at $2 \times 10^{5}$ cells/well) in complete medium and incubated at $37^{\circ} \mathrm{C}$ the day prior to transfection. DU145 and DU145-DR cells were transfected with $50 \mathrm{nM}$ small interfering RNA (siRNA) control and SmartPool anti-human CLU-siRNA (cat. no. L-019513-00-0005; GE Healthcare Dharmacon, Inc., 
Lafayette, CO, USA) using Lipofectamine 2000 (Invitrogen; Thermo Fisher Scientific, Inc.) as a transfection reagent. The transfection of PC3 AG and PC3-D12 cell lines was carried out with $5 \mathrm{nM}$ siRNA using Dharmafect 2 (GE Healthcare Dharmacon, Inc.) as a transfection reagent. At $5 \mathrm{~h}$ following transfection, the medium was replaced and GTN treatments at $100 \mu \mathrm{M}$ were performed. Cells were incubated for $72 \mathrm{~h}$.

To establish the DU145-DR fluorescent cell line, DU145-DR cells were stably transfected with $2.5 \mu \mathrm{g} / \mu \mathrm{l}$ pCMV-DsRed plasmid (Clontech Laboratories, Inc., Mountainview, CA, USA), supplemented with $60 \mu \mathrm{l}$ Superfect (Qiagen $\mathrm{GmbH}$, Hilden, Germany). The positive cells were selected using Geniticin $(750 \mu \mathrm{g} / \mathrm{ml}$, determined as the minimum effective concentration to kill non-resistant cells; Gibco; Thermo Fisher Scientific, Inc.) and sorted by flow cytometry following 2 weeks of selection.

Western blotting. Western blotting was performed to examine the expression of clusterin and pro-GDF-15. Cells were treated with the indicated concentrations of GTN in presence or absence of human recombinant GDF-15. Cells were lysed in boiling buffer (150 mM NaCl, $150 \mathrm{mM}$ TrisHCl pH 7.4, $1 \%$ SDS and $1 \mathrm{mM}$ sodium orthovanadate) supplemented with protease inhibitor cocktail (Roche Diagnostics, Basel, Switzerland). The viscosity of the samples was reduced by several passages through a 26-gauge needle. Proteins concentrations were measured using the $\mathrm{DC}^{\mathrm{TM}}$ protein assay kit (Bio-Rad Laboratories, Inc., Hercules, CA, USA). The proteins (from whole-cell extracts or cell supernatants) were separated by $12 \%$ SDS-PAGE and transferred to nitrocellulose membrane (Bio-Rad Laboratories, Inc.). After blocking non-specific binding sites overnight at $4^{\circ} \mathrm{C}$ by $5 \%$ non-fat milk in PBS with Tween-20 $0.1 \%$, the membranes were incubated with the appropriate primary antibody: Monoclonal mouse anti-human clusterin (MAB29372; 1:1,000) polyclonal goat anti-human GDF-15 (BAF940; 1:1,000) (both from R\&D Systems, Inc.), monoclonal mouse anti-human $\beta$-actin (SC-47778; 1:1,000; Santa Cruz Biotechnology, Inc., Dallas, TX, USA) or monoclonal mouse anti-human heat shock cognate 70 (HSC70; SC-7298; 1:1,000; Santa Cruz Biotechnology, Inc.) overnight at $4^{\circ} \mathrm{C}$, then with the secondary antibody peroxidase AffiniPure goat anti-mouse IgG (H+L; 115-035-003; 1:5,000; Jackson ImmunoResearch Europe, Ltd., Newmarket, UK) or streptavidin protein Dylight 800 (1:10,000; Thermo Fischer Scientific, Inc.) for $1 \mathrm{~h}$ at room temperature. The level of protein expression was analyzed using the Odyssey imaging system (LI-COR Biosciences, Lincoln, NE, USA) or the Molecular Imager Chemi Doc ${ }^{\mathrm{TM}}$ XRS+ (Bio-Rad Laboratories, Inc.). $\beta$-actin or HSC70 were used as loading control for cell extracts, and Ponceau red (Sigma-Aldrich; Merck KGaA) staining was used as the loading control for cell supernatants. Densitometric analyses of protein levels were performed using ImageJ $1.52 \mathrm{a}$ software (National Institutes of Health, Bethesda, MD, USA).

Zebrafish model. All zebrafish experiments were conducted according to the French and European Union guidelines concerning laboratory animal handling. The animal procedures described were reviewed and approved by the local Ethics Committee (C2EA 'Comité d'Ethique en Expérimentation Animale’, Grand Campus Dijon, registered no. 105 by the national Ethics Committee CNREEA 'Comité National de Réflexion Ethique sur l'Expérimentation Animale'). In the present study a transgenic zebrafish line flila: Enhanced Green Fluorescent Protein (EGFP) expressing EGFP in endothelial cells under the flila promoter was used (Zebrafish International Resource Center, University of Oregon, Eugene, OR, USA). This model allows the following of eventual neovascularization at the yolksac level following a microinjection of tumor cells (41). Adult zebrafish (15 males and 15 females) were maintained in a recirculating aquaculture system (Müller \& Pfleger GmbH \& Co. KG, Rockenhausen, Germany) with a temperature range of $26-28^{\circ} \mathrm{C}$, and a $14 / 10-\mathrm{h}$ light/dark cycle as previously described (41). They were fed twice a day with dried flake food. The mean ranges for conductivity and $\mathrm{pH}$ in the system were $600-700 \mu \mathrm{S}$ and $6.0-8.0$, respectively. At 2 days prior to the xenotransplantation, males and females were placed in the same tanks and mating was triggered by light stimuli the following day. Eggs were collected in sourcing water a few hours following the fertilization, counted, sorted and up to 50 eggs placed at $28^{\circ} \mathrm{C}$ per Petri dish.

Xenotransplantation and treatment procedure. Zebrafish larvae were dechorionized by pronase $(1 \mathrm{mg} / \mathrm{ml}$; Roche Diagnostics) for $20 \mathrm{~min}$ prior to micro-injection and arrayed on a Petri dish. The injection of DsRed expressing DU145-DR cells was carried out under a fluorescence magnifying glass (Leica MZFLII) using micro-injectors (Eppendorf Femtojet) (20-100 tumor cells/injection) as described previously $(41,42)$. The injected larvae were incubated at $32^{\circ} \mathrm{C}$ in saturated humid conditions. At 1 day following the injection, the larvae were anesthetized with $0.17 \mathrm{mg} / \mathrm{ml}$ tricaine (Sigma-Aldrich; Merck $\mathrm{KGaA}$ ) and sorted according to their red fluorescence using a Leica MZFLIII fluorescence stereomicroscope bearing appropriated filters with 12.5 :1 zoom leading to a maximum magnification of $x 800$ with $10 x$ micro objectives (Leica Microsystems, Inc., Buffalo Grove, IL, USA). The positive larvae were then treated with $10 \mu \mathrm{M}$ GTN for 5 days. Non-positive larvae were euthanized with tricaine $(0.3 \mathrm{mg} / \mathrm{ml})$.

Reverse transcription-quantitative polymerase chain reaction $(R T-q P C R)$. Total RNA was isolated from zebrafish larvae using TRIzol (Invitrogen; Thermo Fisher Scientific, Inc.) and $1 \mu \mathrm{g}$ RNA was reverse transcribed using Moloney murine leukemia virus reverse transcriptase with random hexamers (both from Promega Corporation) according to manufacturer's protocol. cDNA was quantified by qPCR on a 7500 Fast system (Life Technologies; Thermo Fisher Scientific, Inc.) using the standard SYBR-Green PCR Master mix detection protocol (Invitrogen; Thermo Fisher Scientific, Inc.). Standard reaction volume was $20 \mu \mathrm{l}$ and contained $10 \mu \mathrm{l}$ SYBR-Green mix, $2 \mu \mathrm{l}$ cDNA template and $125 \mathrm{nM}$ of primers. The thermocycling conditions were composed of an activation step at $50^{\circ} \mathrm{C}$ for $2 \mathrm{~min}$, a denaturation step at $95^{\circ} \mathrm{C}$ for $10 \mathrm{~min}$, followed by 45 cycles of denaturation at $95^{\circ} \mathrm{C}$ for $15 \mathrm{sec}$ and primer annealing/extension at $60^{\circ} \mathrm{C}$ for $1 \mathrm{~min}$. The final step was a $60^{\circ} \mathrm{C}$ incubation for $1 \mathrm{~min}$. All reactions were performed in triplicate. The mRNA abundance was calculated according to the $2^{-\Delta \Delta \mathrm{Cq}}$ method analysis (43). Expression of all genes was normalized respective to human L32 and zebrafish actin expression levels. The primers used were as 

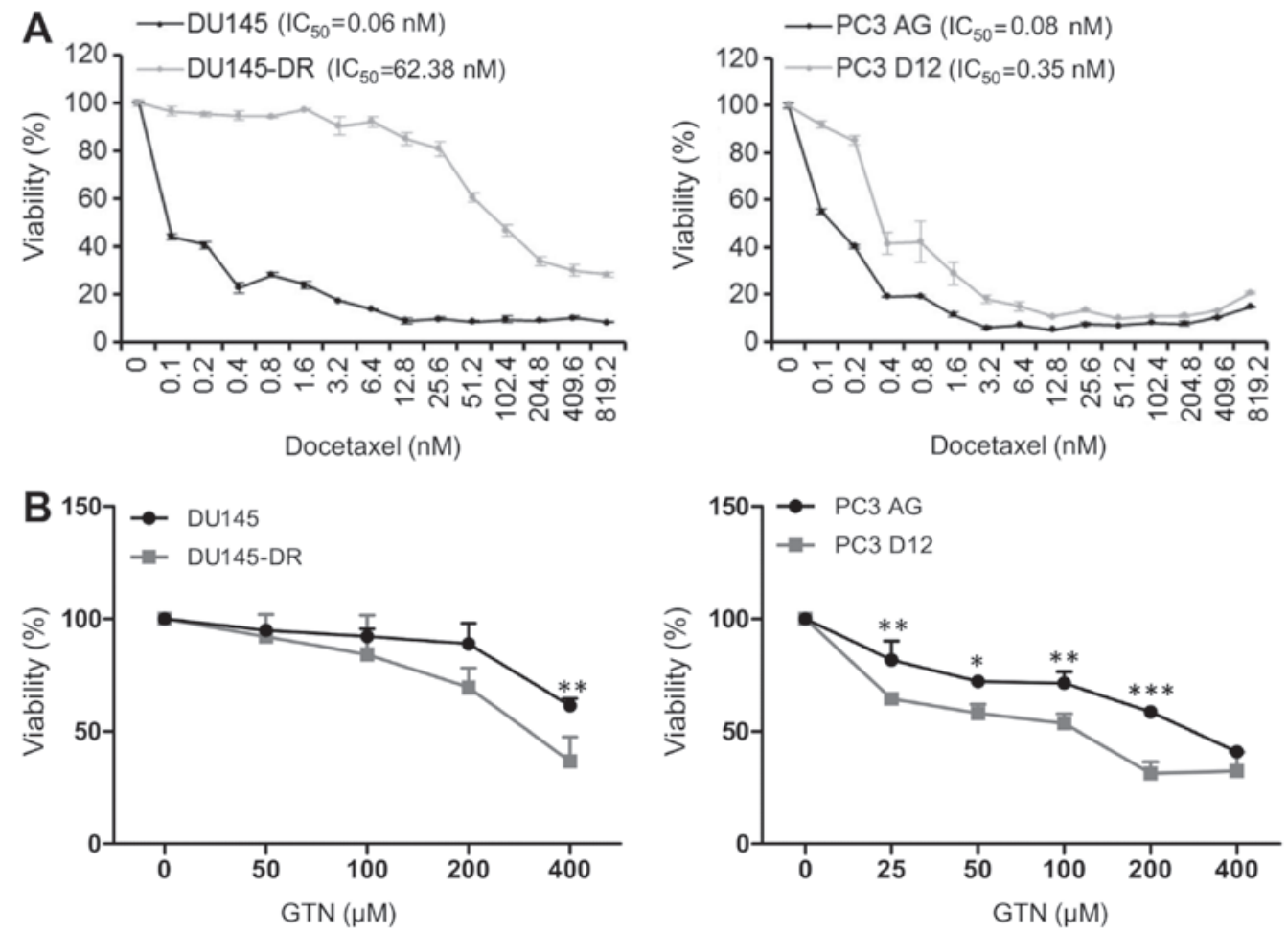

Figure 1. Docetaxel-resistant mCRPC cells are sensitive to GTN. Docetaxel-resistant (DU145-DR and PC3 D12) or parental (DU145 and PC3 AG) mCRPC cell lines were treated for $72 \mathrm{~h}$ with a range of (A) docetaxel or (B) GTN concentrations as indicated. Cell viability was determined and the half maximal inhibitory concentration values following docetaxel and GTN treatments were estimated from the concentration-response curve. Data are presented as the mean \pm SD of three independent experiments. Significant differences were determined by applying a two-way analysis of variance test for each pair (DU145 vs. DU145-DR and PC3 vs. PC3 D12). "P<0.05, ${ }^{* *} \mathrm{P}<0.01$ and ${ }^{* * * *} \mathrm{P}<0.001$ vs. DU145-DR or PC3 D12 as appropriate. mCRPC, metastatic castration resistant prostate cancer; GTN, glyceryl trinitrate; ANOVA, analysis of variance.

follows: Human clusterin, forward, 5'-CCG CAA AAA GCA CCG GGA GGA-3' and reverse, 5'-GGG CTG CAG CTC ATC TTG GGG-3'; zebrafish clusterin, forward, 5'-AAG AGG AAG AAT CAA AGC AGG TGT-3' and reverse, 5'-GTA GAG GAG AAA CAG CCC CAG-3'; human cyclin D1, forward, 5'-CCC TGA CAG TCC CTC CTC T-3' and reverse, 5'-GAA GGG GGA AAG AGC AAA G-3'; human L32, forward, 5'-TGT CCT GAA TGT GGT CAC CTG-3' and reverse, 5'-CTG CAG TCT CCT TGC ACA CCT-3'; and zebrafish actin, forward, 5'-CCC AGA CAT CAG GGA GTG AT-3' and reverse, 5'-CAC AAT ACC GTG CTC AAT GG-3'.

Cytokine array analysis. Cell culture supernatants from DU145, DU145-DR, PC3 AG and PC3-D12 were analyzed using RayBio ${ }^{\circledR}$ human cytokine array C3 and C9 according to the manufacturer's recommendation (RayBiotech, Inc., Norcross, GA, USA).

Statistical analysis. Data are presented as the mean \pm standard deviation of the indicated number of experiments. Significant differences were evaluated using Student's t-test, one-way analysis of variance with a post-hoc Tukey's test or two-way analysis of variance with a post-hoc Bonferroni's test. $\mathrm{P}<0.05$ was considered to indicate a statistically significant difference.

\section{Results}

Docetaxel-resistant human prostatic cancer cells are sensitive to GTN. In the current study, two human prostatic cancer cell lines were utilized, both chemosensitive (DU145 and PC3AG) and chemoresistant (DU145-DR and PC3-D12) to docetaxel. In order to generate DU145-DR cells, DU145 cells were treated with increasing concentration of docetaxel. The cell viability in the chemosensitive and chemoresistant cells to docetaxel was first assayed by MTS assay in the presence of a range of docetaxel concentrations. In response to increasing concentrations of docetaxel, an increased survival rate was observed in prostatic resistant cancer cell lines DU145-DR and PC3-D12 in comparison with the parental cells, which confirmed the docetaxel resistant phenotype of DU145-DR and PC3-D12. DU145-DR and PC3 D12 cells demonstrated a greater resistance to docetaxel compared with their parental counterparts (DU145 DR IC $_{50}=62.38 \mathrm{nM}$ vs. DU145 $\mathrm{IC}_{50}=0.06 \mathrm{nM}$; PC3D12 $\mathrm{IC}_{50}=0.35 \mathrm{nM}$ vs. PC3-AG=0.08 nM; Fig. $1 \mathrm{~A}$ ).

Notably, when compared with the parental cell lines, DU145-DR and PC3-D12 cell lines chemoresistant to docetaxel exhibited increased sensitivity to the antiproliferative effect of GTN used at various concentrations (ranging from 25-400 $\mu \mathrm{M}$ ) over a time course of $72 \mathrm{~h}$ (Fig. 1B).

GTN-induced cytoxicityis attributabletodifferentialregulation of $C L U$. Having demonstrated that docetaxel-resistant cell lines were more prone to GTN cytotoxicity, it was attempted to identify the molecular mechanisms underlying this effect. The level of clusterin, a key docetaxel resistant marker in human prostatic cancer, was investigated. The basal levels of the secretory form of clusterin (sCLU; anti-apoptotic function) in the supernatant from docetaxel-resistant and parental mCRPC 

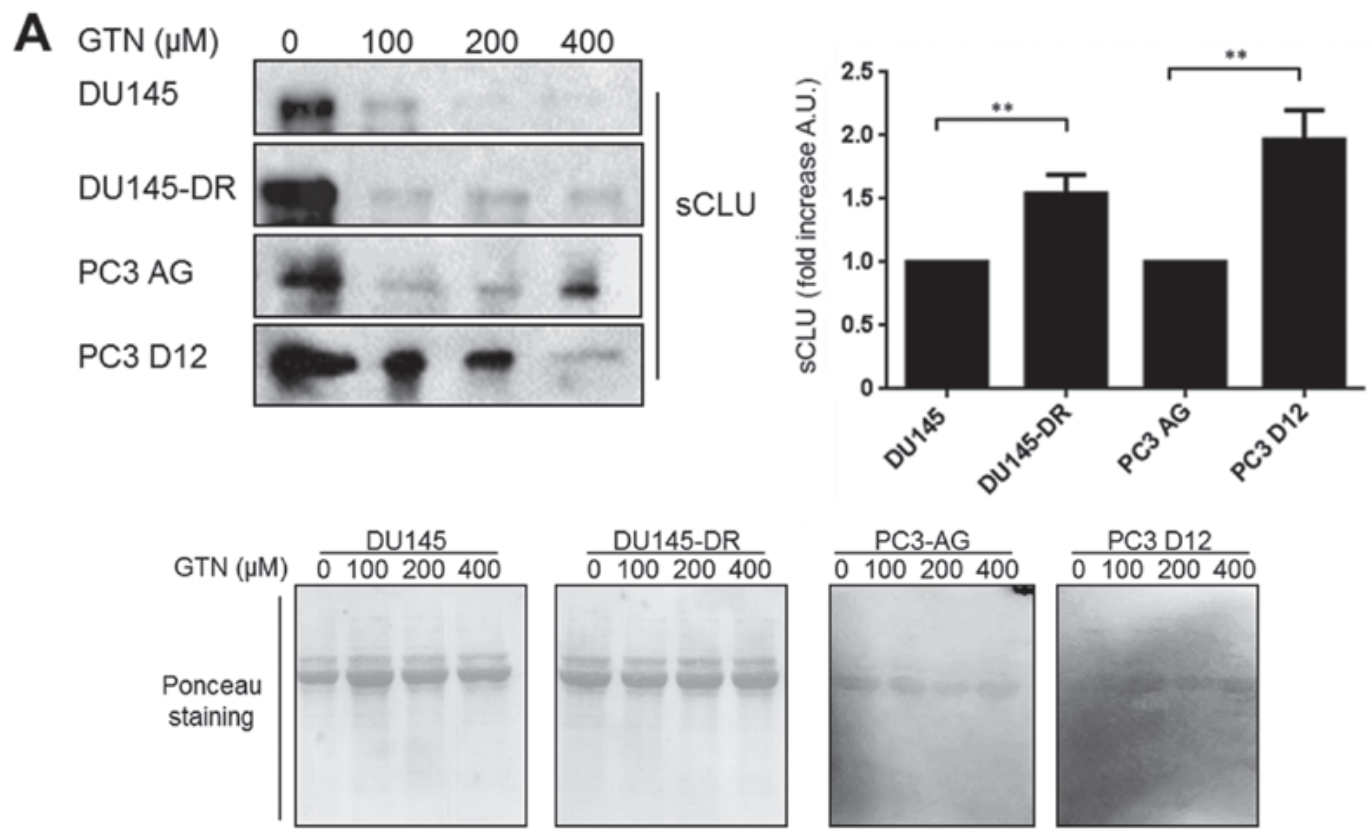

B
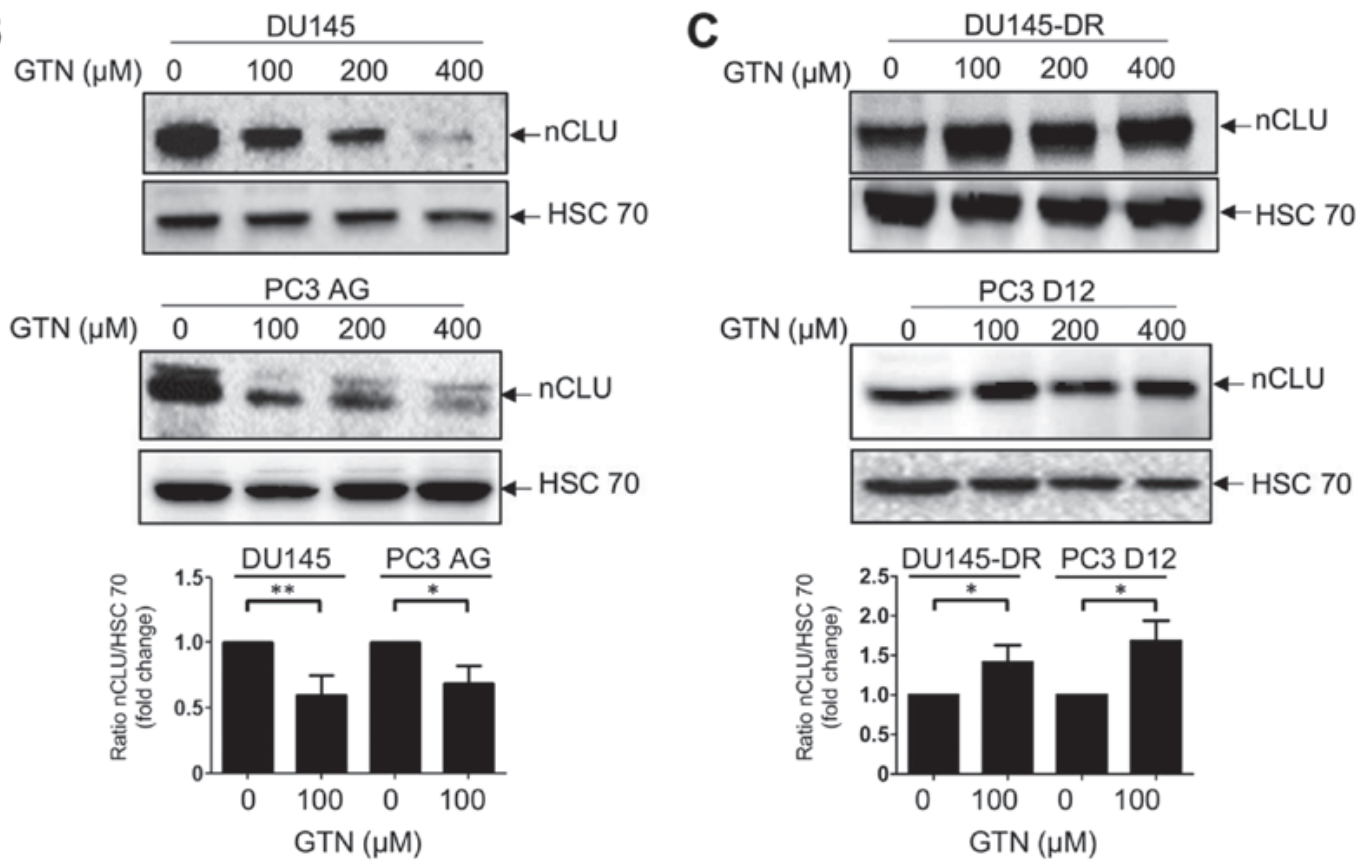

Figure 2. Differential regulation of clusterin isoforms by GTN. Western blot analysis of sCLU and nCLU levels in (A) culture supernatants and (B and C) whole-cell extracts from mCRPC cells. The blots presented are representative of three independent experiments. The histograms present quantification of sCLU and nCLU using densitometric analyses of three independent experiments. (A) The data are presented as mean-fold increase $( \pm$ standard deviation) over basal level in DU145 and PC3 AG cells. The blots were stained with Ponceau solution as loading control of cell culture supernatant samples. (B and C) Docetaxel-sensitive/resistant mCRPC cell lines were treated for $72 \mathrm{~h}$ with GTN concentrations ranging from $0-400 \mu \mathrm{M}$. The constitutive HSC70 was used as loading control. The immunoblotting analysis of sCLU and nCLU in both (B) docetaxel-sensitive and (C) -resistant cells (PC-3 or DU145) was performed in parallel. Data represent the mean ratio nCLU/HSC70 \pm standard deviation in mCRPC cells treated with GTN (100 $\mu \mathrm{M})$ over basal values (cells left untreated) from three independent experiments. Statistically significant differences were determined using a Student's t-test. " $\mathrm{P}<0.05$; ${ }^{* * *} \mathrm{P}<0.01$. GTN, glyceryl trinitrate; sCLU, soluble clusterin; nCLU, nuclear clusterin; mCRPC, metastatic castration resistant prostate cancer; HSC70, heat shock cognate 70.

cell lines were evaluated. It was observed that the level of sCLU was significantly higher in docetaxel-resistant cells compared with parental cells (Fig. 2A). Notably, a reduction in sCLU protein expression was observed in all cell lines upon GTN treatment at $100 \mu \mathrm{M}$ for $72 \mathrm{~h}$, except for the PC3-D12 cells, in which a reduction of the level of expression was observed only with higher concentrations of GTN $(400 \mu \mathrm{M})$. The nCLU protein expression level was then evaluated. It was observed that GTN induced a significant reduction in the levels of nCLU compared with control in the parental cells (Fig. 2B) and an increase in the levels of nCLU compared with control in the resistant cell lines (Fig. 2C), in accordance with their sensitivity to GTN-induced cytotoxicity (Fig. 1B). These results may suggest that GTN regulates the balance of proapoptotic and antiapoptotic levels of expression of CLU, thereby favoring death over survival.

The biological involvement of the modulation of CLU expression in GTN-induced cytotoxicity for 


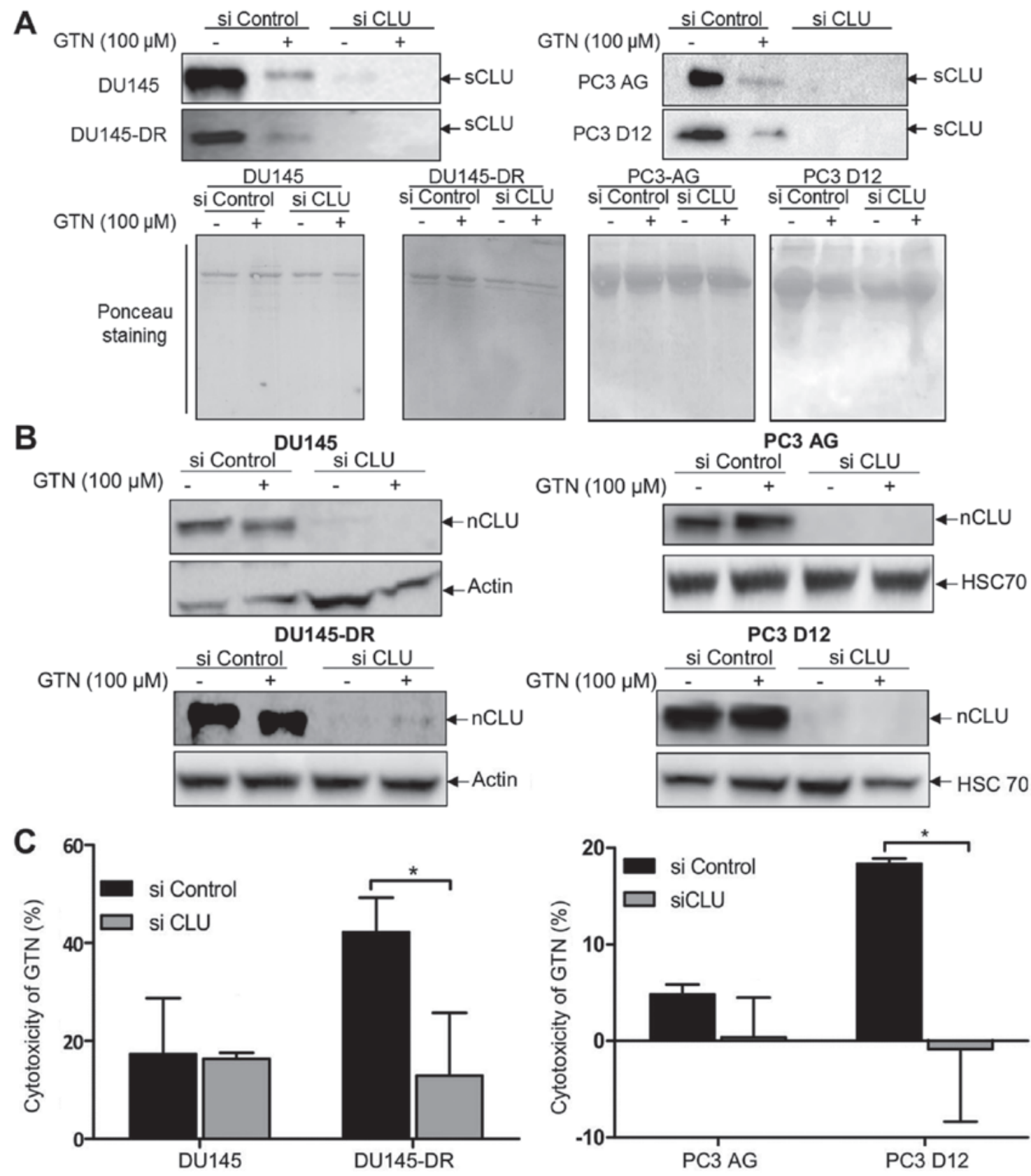

Figure 3. GTN-induced cytotoxicity is dependent on levels of clusterin isoforms. Analysis of (A) sCLU and (B) nCLU levels by western blotting with extracts obtained from mCRPC cell lines transiently transfected with control siRNA (si-Control) or clusterin siRNA (si-CLU) and treated or not with $100 \mu \mathrm{M}$ GTN for $72 \mathrm{~h}$. sCLU level was evaluated in the culture supernatants and nCLU in total lysate extracts. Ponceau staining is shown as loading control for analysis of sCLU in cell culture supernatants samples. $\beta$-actin and HSC70 (for analysis of nCLU in whole-cell extracts) were used as loading controls. GTN-induced cytotoxicity on siRNA transfected docetaxel-sensitive/resistant human prostate cancer cells was measured. (C) Cytotoxicity was indirectly determined by subtracting the viability values from the total values (100\%) in non-treated cells. Transfected mCRPC cells were treated with $100 \mu \mathrm{M}$ GTN for $72 \mathrm{~h}$. Data represent the mean \pm standard deviation of 3 independent experiments. Significant differences were determined by using a two-way analysis of variance test. ${ }^{*} \mathrm{P}<0.05$. GTN, glyceryl trinitrate; sCLU, soluble clusterin; nCLU, nuclear clusterin; siRNA, small interfering ribonucleic acid; HSC70, heat shock cognate 70; mCRPC, metastatic castration resistant prostate cancer.

docetaxel-resistant cell lines was then examined. Thus, whether CLU silencing (sCLU and nCLU) could affect the cytotoxic effects of GTN in the four human prostate cancer cell lines was explored. As presented in Fig. 3A and B, western blotting indicated that sCLU and nCLU levels of expression were dramatically decreased with CLU siRNA compared with controls, both in the absence or presence of GTN (even though the transfection reagent increases the amount of CLU). Furthermore, sensitive cells (DU145 and PC3-AG cells) transfected with CLU siRNA and then treated with GTN did not exhibit any marked changes in cytotoxicity compared with the control (cells transfected with control siRNA). In accordance with our previous findings (Fig. 1B), docetaxel-resistant control cells (control siRNA) were more sensitive to GTN-induced cytotoxicity than the parental control cells (control siRNA). However, clusterin silencing significantly reduced the cytotoxic effect of GTN in both DU145-DR and PC3-D12 docetaxel-resistant cells compared with the control cells to reach a similar level of cytotoxicity observed in sensitive cells (Fig. 3C). 
A

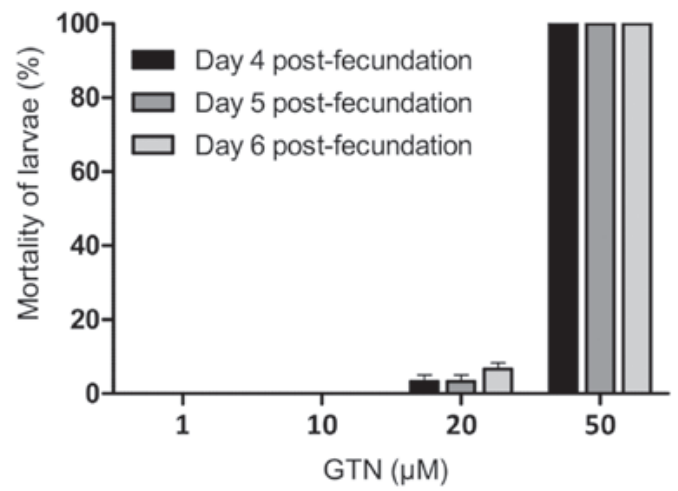

B

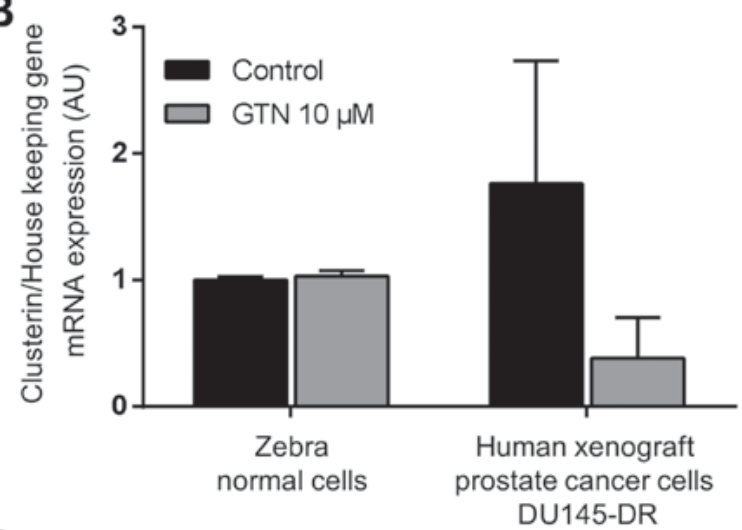

C

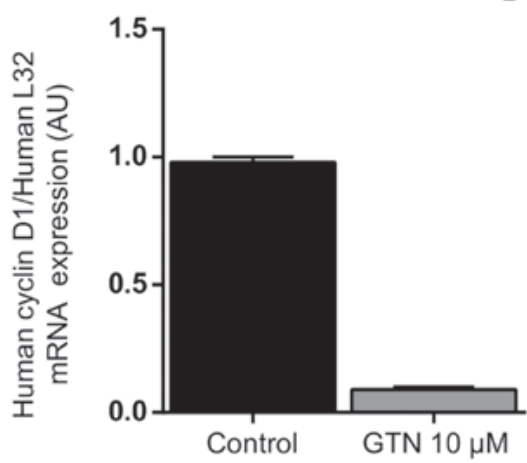

Figure 4. GTN downregulates the expression of human clusterin and cyclin D1 at a transcriptional level. (A) Non-xenotransplanted larvae were treated with increasing concentrations of GTN $(1,10,20$ and $50 \mu \mathrm{M})$ for 3,4 or 5 days to determine their sensitivity to the nitric oxide donor. A batch of 10 larvae was used for each treatment. Data represent the mean \pm standard error of the mean. Larvae were xenotransplanted with DU145-DR docetaxel-resistant human metastatic castration resistant prostate cancer cells then treated with $10 \mu \mathrm{M}$ of GTN for 5 days. (B) Zebrafish and human clusterin expression and (C) human cyclin D1 expression were analyzed in xenotransplanted larvae by reverse transcription-quantitative polymerase chain reaction. Each condition was obtained from the mRNA extracted from the batch of 10 larvae. Data are representative of 2 independent experiences. GTN, glyceryl trinitrate.

Taken together, these findings indicate that the cytotoxic effect of GTN in sensitive cells is not dependent of clusterin expression. On the contrary, the cytotoxic effect of GTN in docetaxel-resistant cells is dependent of clusterin expression. Although the present study cannot distinguish the role of sCLU and nCLU (siRNA CLU indifferently targets sCLU and nCLU), these results suggest that GTN cytotoxicity may be most likely dependent of the nuclear form of the clusterin, upregulated by GTN treatment in docetaxel-resistant cells.

GTN modulates the level of human clusterin in vivo. The role of GTN in modulating the level of clusterin expression in human prostatic cancer cells in vivo was then investigated by experimental approaches in zebrafish. The tolerance of zebrafish larvae (4-6 days post-fertilization) to GTN was tested and mortality rate was recorded. All larvae treated with 1 and $10 \mu \mathrm{M}$ GTN during the 4, 5 and 6 days post-fertilization exposure sets survived. For the larvae exposed to $20 \mu \mathrm{M}$ GTN, the mortality rates were $3.3 \%$ in the 4 and 5 days post-fertilization and $6.6 \%$ in the 6 days post-fertilization group. All zebrafish larvae exposed to $50 \mu \mathrm{M}$ died in each stage of larval development tested (Fig. 4A). The maximum tolerated dose for GTN selected for further studies was $10 \mu \mathrm{M}$, corresponding to $100 \%$ zebrafish larvae survival. A DU145-DR xenograft model in zebrafish was then generated, and the effects of GTN on the level of clusterin transcription were assessed in vivo. Following GTN treatment, it was observed that the level of zebrafish clusterin gene expression remains unchanged compared with controls, whereas the level of human clusterin gene expression in human tumor cells was reduced (Fig. 4B). The level of expression of human cyclin D1 upon GTN treatment was also measured. Following 5 days post-xenotransplantation exposure of GTN, the level of expression of cyclin D1 gene (key cell cycle regulator) was decreased (Fig. 4C), which suggests a reduction in the amount of clusterin in DU145-DR cells and the inhibition of proliferation status of these tumor cells in vivo.

GTN and GDF-15 modulate the level of CLU. As cytokines such as TGF- $\beta$ can regulate the level of expression of CLU (44), the presence of cytokines in the docetaxel-resistant and sensitive cellular model (using a cytokine array, data not shown) was investigated to better delineate the role of CLU in cancer cell sensitivity to GTN. A signal was detectable for GDF-15, a member of TGF- $\beta$ family, that lead us to evaluate the impact of GTN on GDF-15 regulation. Following GTN exposure, the intracellular form of GDF-15 (pro-GDF-15, a precursor form of GDF-15) is differentially regulated between sensitive and docetaxel-resistant prostate cancer cells. It is significantly increased in docetaxel-resistant cells with the lower concentration of GTN $(100 \mu \mathrm{M})$ compared with control, but not in parental cells (Fig. 5A). DU145 and DU145-DR cells were not used here due to an undetectable level of the intracellular form of GDF-15 (data not shown).

A GDF-15 recombinant protein was used to elucidate whether it could affect the level of expression of sCLU and nCLU in PC3 AG and PC3 D12 cell lines. Cells were treated with recombinant GDF-15 or GTN or the combination of both. Notably, GDF-15 induces sCLU and nCLU levels of expression mainly in PC3 D12 docetaxel-resistant cells. However, when GTN is added to GDF-15 treatment, the level of sCLU is completely reduced and the level of nCLU is increased compared with GDF-15 treatment alone (Fig. 5B). Meanwhile, the effect of GTN, GDF-15 and GTN/GDF-15 was tested on the viability of PC3 AG and PC3 D12 cells. Although no significant effect was observed on PC3 AG viability under these conditions, recombinant GDF-15 along with GTN in docetaxel-resistant PC3 D12 cells significantly abrogates the GTN-induced decrease in viability in these cells (Fig. 5C). This effect is in accordance with a lower amount of nCLU in comparison with GTN treatment alone (Fig. 5B). Conversely, although recombinant GDF-15 treatment resulted in an increase in nCLU (pro-apoptotic) in PC3 cell lines, GDF-15 
A
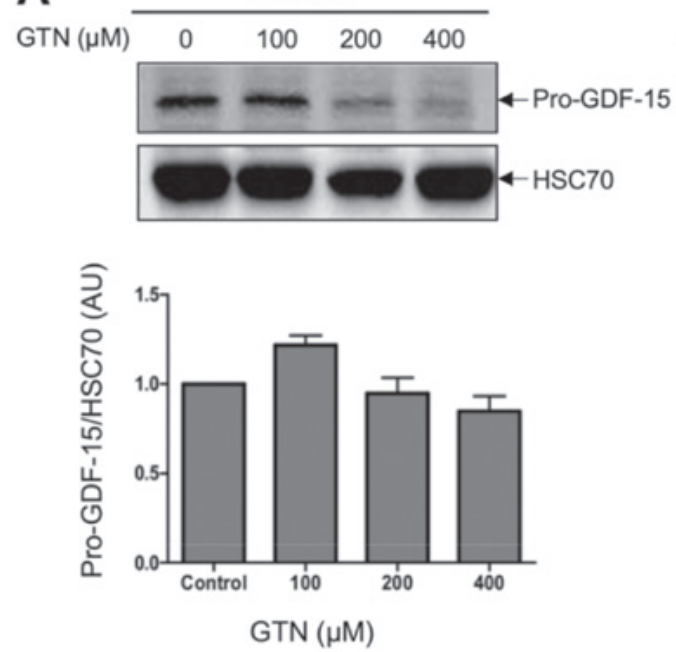

B

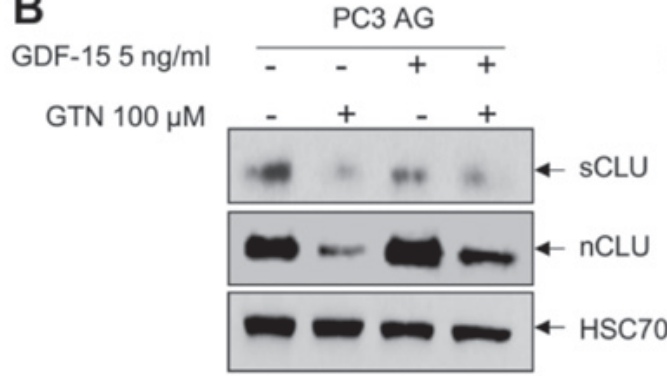

C

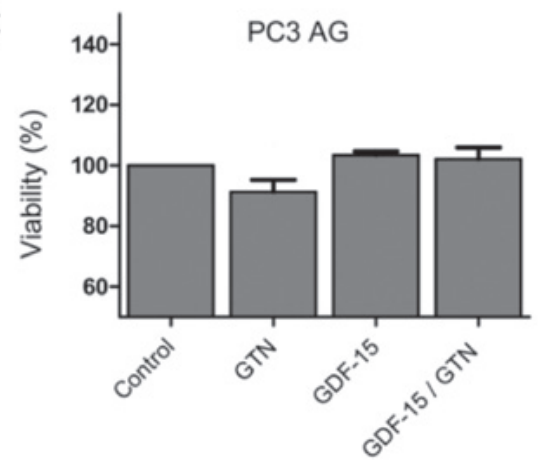

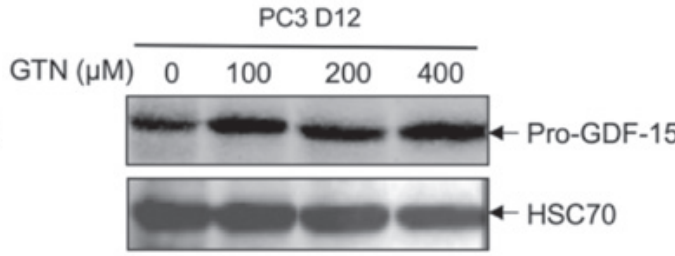
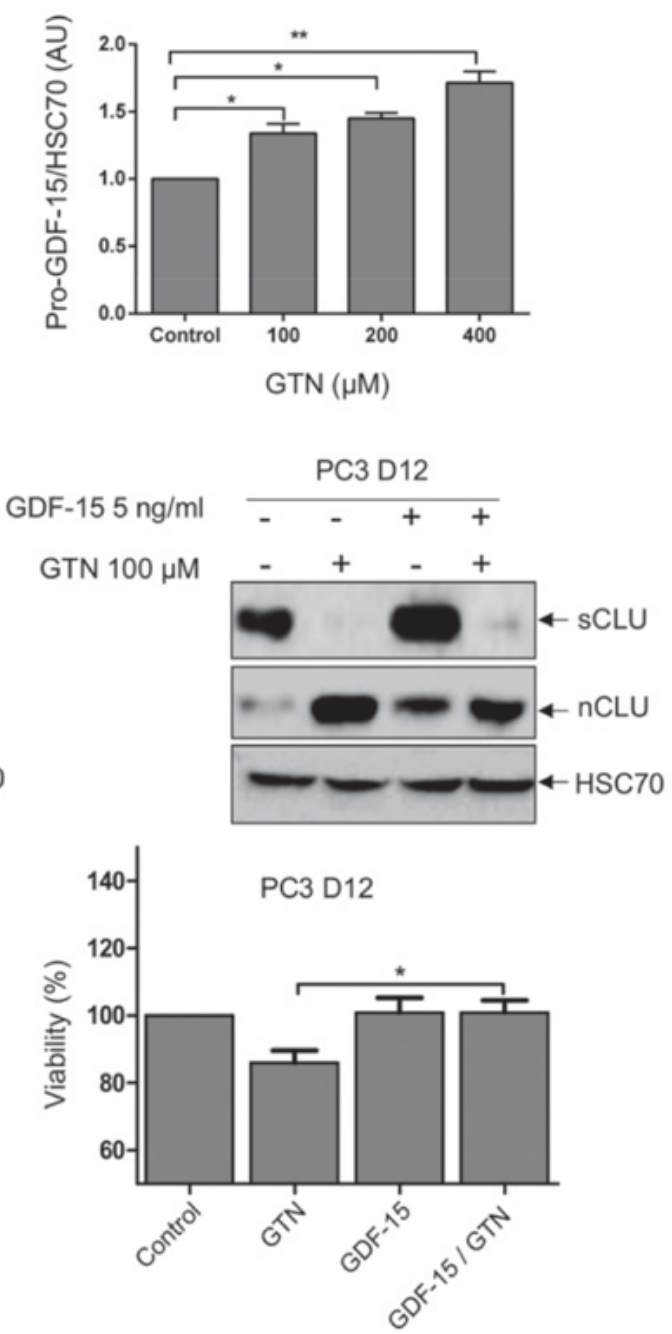

Figure 5. The regulatory effect of GTN on clusterin levels involves GDF-15. (A) PC3-AG and PC3-D12 mCRPC cell lines were treated for $72 \mathrm{~h}$ with GTN concentrations ranging from $0-400 \mu \mathrm{M}$ and the pro-GDF-15 levels were evaluated by western blotting. The histograms present ratio expression of pro-GDF-15 over HSC70 using densitometric analyses. (B) sCLU and nCLU levels in PC3-AG and PC3-D12 docetaxel sensitive/resistant mCRPC cells were analyzed by western blotting. Cells were treated or not with $100 \mu \mathrm{M}$ GTN in the presence or absence of recombinant GDF-15 (5 ng/ml). These results are representative of three independent experiments. HSC70 protein was used as protein loading control. (C) Cells were treated or not with $100 \mu \mathrm{M}$ of GTN, and with or without $5 \mathrm{ng} / \mathrm{ml}$ recombinant GDF-15. The viability of the cells was measured. The error bars represent mean \pm SD of three independent experiments. Significant differences were determined using a one-way analysis of variance test. ${ }^{\prime} \mathrm{P}<0.05 ;{ }^{* *} \mathrm{P}<0.01$. GTN, glyceryl trinitrate; GDF-15, growth and differentiation factor-15; mCRPC, metastatic castration resistant prostate cancer; HSC70, heat shock cognate 70; sCLU, soluble clusterin; nCLU, nuclear clusterin.

treatment did not result in an increase in cytotoxicity. Due to its various biological functions and role in other signaling pathways, its cytotoxicity could have been counteracted.

Together, these results demonstrate that GTN promotes a differential regulation of the level of sCLU and nCLU in favor of a cytotoxic effect in docetaxel-resistant PC3 D12 cells which appears to be associated with the level of GDF-15.

\section{Discussion}

In an attempt to overcome resistance to docetaxel-based therapy in mCRPC, the effect of the NO donor GTN was studied in docetaxel-resistant human prostatic cancer cells (PC3-D12 and DU145-DR) in comparison with the docetaxel-sensitive parental counterpart. GTN was revealed to be more effective in inhibiting cell viability in docetaxel-resistant cells than in docetaxel-sensitive cells. It was observed that GTN regulates the level of expression of two known markers of resistance in mCRPC, CLU and GDF-15. More precisely, a differential regulation of soluble and nuclear CLU isoforms in docetaxel sensitive and resistant prostate cancer cells by GTN was observed. Also, GTN modulated CLU isoforms in favor of a cytotoxic effect associated with increased nCLU pro-death isoform and decreased sCLU cytoprotective 
isoform in docetaxel resistant cells. Notably, targeting CLU expression by siRNA abrogated the ability of GTN to sensitize docetaxel-resistant cells. Altogether an association between the levels of nCLU expression and GTN-induced cytotoxicity was demonstrated.

These findings support the hypothesis that the response of docetaxel-resistant mCRPC cells to GTN is governed by the balance between the pro-death and cytoprotective isoforms of the CLU protein. These findings suggest that docetaxel resistance is mediated to a certain extent by sCLU and that GTN can overcome docetaxel resistance. CLU is a key contributor in mediating survival in chemoresistant cancer cells. A number of studies have demonstrated the cytoprotective role of sCLU against docetaxel in prostate cancers and multiple chemotherapeutic agents in a wide range of late-stage tumors $(45,46)$. Mechanistically, a previous report highlighted the importance of protein kinase B (Akt) pathway activation, responsible for sCLU induction in docetaxel resistance in prostate cancer cells (15). Notably, an inhibitory effect of NO donors S-Nitroso-N-Acetyl-D,L-Penicillamine and S-nitrosoglutathion on Akt pathway activation through S-nitrosylation of the kinase at cysteine 224 has been described (47). Notably, the present study demonstrated in vivo, in a xenograft zebrafish model, the ability of GTN to specifically regulate the level of human clusterin expression in cancer cells and most likely the growth in vivo of xenografted human DU145-DR cells. The use of xenograft human prostate cancer cell models have already been revealed to be a useful tool to develop functional cancer models using PC3 cells (42) or to evaluate docetaxel treatment in DU145-xenografted zebrafish (48).

Altogether these findings suggest that GTN could act as a negative transcriptional regulator of sCLU, but the exact mechanism remains unclear. Given that the Akt pathway is commonly activated in several human cancers it is reasonable to speculate that NO donors may be exploited for counteracting sCLU-dependent docetaxel resistance. Furthermore, Zhou et al (16) demonstrated that acquired resistance to docetaxel in prostate cancer cells was linked to sCLU induction triggered by High Mobility Group Box 1 (HMGB1) produced from dying cells in a HMGB1/Toll Like Receptor 4 - Receptor for Advanced Glycation End-products/sCLU pathway. This pathway involves the activation of the transcription factor $\mathrm{NF}-\kappa \mathrm{B}$ to promote sCLU gene expression. Notably, it has been demonstrated that $\mathrm{NF}-\kappa \mathrm{B}$ activity can be inhibited by S-nitrosylation of critical thiol in both p65 and p50 subunits $(49,50)$.

The inhibition of sCLU in prostate cancer and its impact on the cytotoxic effect of various chemotherapeutic agents has been extensively investigated in preclinical studies and provided rationale for the use of CLU antisense inhibitor OGX011 (or custirsen) as a therapeutic target (51-55). Following encouraging results of phase II clinical studies, two phase III clinical trials for custirsen in combination with docetaxel or cabazitaxel and prednisone for patients with MCRPC but no survival benefit was reported in patients treated with the combination compared with patients treated with chemotherapeutic agents alone $(56,57)$. The disappointing result from phase III clinical trials may suggest that a therapeutic strategy directed against sCLU alone is not sufficient and that a therapeutic strategy that would module the two isoforms (sCLU and nCLU) in favor of an antitumoral response may present an interesting strategy.

The nuclear sub-localization of CLU (nCLU) was demonstrated to promote pro-apoptotic signaling in many cells. Kim et al (58) demonstrated that nCLU mediates apoptosis by sequestering BCL-XL, thereby releasing Bax which triggers mitochondria cytochrome $c$ release and activation of caspase-3. The current study demonstrates that GTN treatment enhances the level of nCLU which is correlated with GTN-induced cytotoxicity. The present study is, to the best of our knowledge, the first report on GDF-15-mediated regulation of CLU, and the findings suggest an implication of GDF-15 in the regulatory mechanism of nCLU by GTN. The regulation of CLU by other cytokines, including TGF- $\beta 1$ and interleukin 24, has also been reported, but the mechanism of action remains largely unknown $(59,60)$.

A number of preclinical and clinical studies have demonstrated the role of GTN as an anti-cancer agent for prostate cancer. A phase II study of GTN in patients with prostate cancer has revealed an inhibitory effect on prostate-specific antigen progression following primary treatment failure (surgery or radiotherapy) (61). Notably, it was demonstrated that GTN attenuates hypoxia-induced hypoxic cells and enhances the in vitro (hypoxic PC3 cells) and in vivo antitumor effect of doxorubicin in mice bearing PC3 prostate tumor xenograft model (31). Furthermore, the NO donor DETANONOate was demonstrated to sensitize prostate cancer cells to cisplatin both in vitro and in vivo (32). Therefore, novel approaches for combination therapy strategies (chemotherapy/NO donor) are required for the effective treatment of prostate cancer.

Recently, transcriptomic signatures associated with docetaxel-resistant mCRPC cells were analyzed with the goal of identifying putative new therapeutic target to overcome docetaxel resistance. RNA sequencing analysis revealed upregulation of genes associated with cancer stem cells-like characteristics (62). Further studies would be required to determine whether NO could directly or indirectly affect these targets and molecular pathways to overcome docetaxel resistance.

Taken together, the present results demonstrate that NO donors, such as GTN, may be an interesting therapeutic agent to disrupt the resistant pathways mediated by docetaxel. NO can interfere with multiple signaling pathways involved in resistance to drugs and many NO donors have been demonstrated to sensitize cancer cells to various chemotherapeutic agents (63). In accordance with the literature, the present data support a key role of CLU in cancer chemoresistance with sCLU being overexpressed following intensive exposure of docetaxel. Thus, as GTN differentially modulates the two CLU isoforms (sCLU and nCLU), it makes GTN a promising therapeutic agent to combine with other chemotherapies.

\section{Acknowledgements}

The authors thank Professor B. Watson (University College Dublin, Dublin, Ireland) for the generous gift of PC3 AG and PC3 D12 cells and Professor J. Chluba (Université de Bourgogne Franche-Comté, Dijon, France) who kindly provided access to the zebrafish core facility. 


\section{Funding}

This project was supported by 'Région Bourgogne'. SB is a recipient of a $\mathrm{PhD}$ fellowship from Ligue Contre le Cancer.

\section{Availability of data and materials}

The dataset generated from cytokine arrays are not publicly available to fully exploit data for future research project and publication. All other data generated or analyzed during this study are included in this article.

\section{Authors' contributions}

SB and LM carried out the experiments and contributed to the interpretation of the results. LD carried out experiments with support from LM. SB and LM designed the figures. SR was involved in the establisment of docetaxel-resistant cells. SB wrote the material and methods section. VL conceived, designed, supervised the study and analysed data. JFJ contributed to the elaboration of the project with NI underlining clinical challenges. SP partially co-supervised the work and took the lead in writing the manuscript with support from VL. AB contributed to the interpretation of the results, proposed experiments and reviewed the manuscript. All authors provided critical feedback and helped shape the research, analysis and manuscript.

\section{Ethics approval and consent to participate}

The animal procedures described in the present study were reviewed and approved by the local Ethics Committee of the University of Burgundy.

\section{Patient consent for publication}

Not applicable.

\section{Competing interests}

The authors declare that they have no competing interests.

\section{References}

1. Wong MCS, Hamilton W, Whiteman DC, Jiang JY, Qiao Y, Fung FD, Wang HH, Chiu PW, Ng EK, Wu JC, et al: Global incidence and mortality of oesophageal cancer and their correlation with socioeconomic indicators temporal patterns and trends in 41 countries. Sci Rep 8: 4522, 2018.

2. Hurwitz M: Chemotherapy in prostate cancer. Curr Oncol Rep 17: 44, 2015.

3. McGrogan BT, Gilmartin B, Carney DN and McCann A: Taxanes, microtubules and chemoresistant breast cancer. Biochim Biophys Acta 1785: 96-132, 2008

4. Zhu ML, Horbinski CM, Garzotto M, Qian DZ, Beer TM and Kyprianou N: Tubulin-targeting chemotherapy impairs androgen receptor activity in prostate cancer. Cancer Res 70: 7992-8002, 2010.

5. Darshan MS, Loftus MS, Thadani-Mulero M,Levy BP, Escuin D, Zhou XK, Gjyrezi A, Chanel-Vos C, Shen R, Tagawa ST, et al: Taxane-induced blockade to nuclear accumulation of the androgen receptor predicts clinical responses in metastatic prostate cancer. Cancer Res 71: 6019-6029, 2011.

6. Hotte SJ: Addressing taxane resistance in metastatic castrationresistant prostate cancer: A focus on chaperone proteins. Future Oncol 13: 369-379, 2017.
7. Magadoux L, Isambert N, Plenchette S, Jeannin JF and Laurens V: Emerging targets to monitor and overcome docetaxel resistance in castration resistant prostate cancer (Review). Int J Oncol 45: 919-928, 2014.

8. Galletti G, Leach BI, Lam L and Tagawa ST: Mechanisms of resistance to systemic therapy in metastatic castration-resistant prostate cancer. Cancer Treat Rev 57: 16-27, 2017.

9. Yao YS, Qiu WS, Yao RY, Zhang Q, Zhuang LK, Zhou F, Sun LB and Yue L: miR-141 confers docetaxel chemoresistance of breast cancer cells via regulation of EIF4E expression. Oncol Rep 33: 2504-2512, 2015.

10. Zu S, Ma W, Xiao P, Cui Y, Ma T, Zhou C and Zhang H: Evaluation of docetaxel-sensitive and docetaxel-resistant proteomes in PC-3 cells. Urol Int 95: 114-119, 2015.

11. Miyake H,Muramaki M, Furukawa J, Kurahashi T and Fujisawa M: Serum level of clusterin and its density in men with prostate cancer as novel biomarkers reflecting disease extension. Urology 75: 454-459, 2010.

12. Zoubeidi A, Chi K and Gleave M: Targeting the cytoprotective chaperone, clusterin, for treatment of advanced cancer. Clin Cancer Res 16: 1088-1093, 2010.

13. Trougakos IP, Djeu JY, Gonos ES and Boothman DA: Advances and challenges in basic and translational research on clusterin. Cancer Res 69: 403-406, 2009.

14. Rohne P, Prochnow H, Wolf S, Renner B and Koch-Brandt C: The chaperone activity of clusterin is dependent on glycosylation and redox environment. Cell Physiol Biochem 34: 1626-1639, 2014.

15. Zhong B, Sallman DA, Gilvary DL, Pernazza D, Sahakian E, Fritz D, Cheng JQ, Trougakos I, Wei S and Djeu JY: Induction of clusterin by AKT - role in cytoprotection against docetaxel in prostate tumor cells. Mol Cancer Ther 9: 1831-1841, 2010.

16. Zhou J, Chen X, Gilvary DL, Tejera MM, Eksioglu EA, Wei S and Djeu JY: HMGB1 induction of clusterin creates a chemoresistant niche in human prostate tumor cells. Sci Rep 5: 15085, 2015.

17. Muhammad LA and Saad F: The role of clusterin in prostate cancer: Treatment resistance and potential as a therapeutic target. Expert Rev Anticancer Ther 15: 1049-1061, 2015.

18. Tellez T, Garcia-Aranda M and Redondo M: The role of clusterin in carcinogenesis and its potential utility as therapeutic target. Curr Med Chem 23: 4297-4308, 2016.

19. Lamoureux F, Thomas C, Yin MJ, Kuruma H, Beraldi E, Fazli L, Zoubeidi A and Gleave ME: Clusterin inhibition using OGX-011 synergistically enhances Hsp90 inhibitor activity by suppressing the heat shock response in castrate-resistant prostate cancer. Cancer Res 71: 5838-5849, 2011.

20. Higano CS: Potential use of custirsen to treat prostate cancer. OncoTargets Ther 6: 785-797, 2013.

21. Chi KN, Hotte SJ, Yu EY, Tu D, Eigl BJ, Tannock I, Saad F, North S, Powers J, Gleave ME, et al: Randomized phase II study of docetaxel and prednisone with or without OGX-011 in patients with metastatic castration-resistant prostate cancer. J Clin Oncol 28: 4247-4254, 2010.

22. Saad F, Hotte S, North S, Eigl B, Chi K, Czaykowski P, Wood L, Pollak M, Berry S, Lattouf JB, et al; Canadian Uro-Oncology Group: Randomized phase II trial of Custirsen (OGX-011) in combination with docetaxel or mitoxantrone as second-line therapy in patients with metastatic castrate-resistant prostate cancer progressing after first-line docetaxel: CUOG trial P-06c. Clin Cancer Res 17: 5765-5773, 2011.

23. Blumenstein B, Saad F, Hotte S, Chi KN, Eigl B, Gleave M and Jacobs C: Reduction in serum clusterin is a potential therapeutic biomarker in patients with castration-resistant prostate cancer treated with custirsen. Cancer Med 2: 468-477, 2013.

24. Moretti RM, Mai S, Montagnani Marelli M, Rizzi F, Bettuzzi S and Limonta P: Molecular mechanisms of the antimetastatic activity of nuclear clusterin in prostate cancer cells. Int $\mathrm{J}$ Oncol 39: 225-234, 2011.

25. Scaltriti M, Santamaria A, Paciucci R and Bettuzzi S: Intracellular clusterin induces $\mathrm{G} 2-\mathrm{M}$ phase arrest and cell death in PC-3 prostate cancer cells. Cancer Res 64: 6174-6182, 2004.

26. Prochnow H, Gollan R, Rohne P, Hassemer M, Koch-Brandt C and Baiersdörfer M: Non-secreted clusterin isoforms are translated in rare amounts from distinct human mRNA variants and do not affect Bax-mediated apoptosis or the NF- $\mathrm{KB}$ signaling pathway. PLoS One 8: e75303, 2013.

27. Huang CY, Beer TM, Higano CS, True LD, Vessella R, Lange PH, Garzotto M and Nelson PS: Molecular alterations in prostate carcinomas that associate with in vivo exposure to chemotherapy: Identification of a cytoprotective mechanism involving growth differentiation factor 15. Clin Cancer Res 13: 5825-5833, 2007. 
28. Zhao L, Lee BY, Brown DA, Molloy MP, Marx GM, Pavlakis N, Boyer MJ, Stockler MR, Kaplan W, Breit SN, et al: Identification of candidate biomarkers of therapeutic response to docetaxel by proteomic profiling. Cancer Res 69: 7696-7703, 2009.

29. Shim $M$ and Eling TE: Protein kinase $C$-dependent regulation of NAG-1/placental bone morphogenic protein/MIC-1 expression in LNCaP prostate carcinoma cells. J Biol Chem 280: 18636-18642, 2005.

30. Patel SA and Hoffman-Censits J: Cabazitaxel in the treatment of metastatic castration-resistant prostate cancer: Patient selection and special considerations. OncoTargets Ther 10: 4089-4098, 2017.

31. Frederiksen LJ, Sullivan R, Maxwell LR, MacdonaldGoodfellow SK, Adams MA, Bennett BM, Siemens DR and Graham CH: Chemosensitization of cancer in vitro and in vivo by nitric oxide signaling. Clin Cancer Res 13: 2199-2206, 2007.

32. Huerta-Yepez S,Baritaki S,Baay-Guzman G,Hernandez-LunaMA, Hernandez-Cueto A, Vega MI and Bonavida B: Contribution of either YY1 or BclXL-induced inhibition by the NO-donor DETANONOate in the reversal of drug resistance, both in vitro and in vivo. YY1 and BclXL are overexpressed in prostate cancer. Nitric Oxide 29: 17-24, 2013.

33. Huerta S,Baay-Guzman G, Gonzalez-Bonilla CR, Livingston EH, Huerta-Yepez $\mathrm{S}$ and Bonavida B: In vitro and in vivo sensitization of SW620 metastatic colon cancer cells to CDDP-induced apoptosis by the nitric oxide donor DETANONOate: Involvement of AIF. Nitric Oxide 20: 182-194, 2009.

34. Gao X, Saha D, Kapur P, Anthony T, Livingston EH and Huerta S: Radiosensitization of HT-29 cells and xenografts by the nitric oxide donor DETANONOate. J Surg Oncol 100: 149-158, 2009.

35. KaliyaperumalK, Sharma AK,McDonald DG,Dhindsa JS, YountC, Singh AK, Won JS and Singh I: S-Nitrosoglutathione-mediated STAT3 regulation in efficacy of radiotherapy and cisplatin therapy in head and neck squamous cell carcinoma. Redox Biol 6: 41-50, 2015.

36. Selvendiran K, Bratasz A, Tong L, Ignarro LJ and Kuppusamy P. NCX-4016, a nitro-derivative of aspirin, inhibits EGFR and STAT3 signaling and modulates Bcl-2 proteins in cisplatin-resistant human ovarian cancer cells and xenografts. Cell Cycle 7: 81-88, 2008.

37. Huerta-Yepez S, Vega M, Escoto-Chavez SE, Murdock B, Sakai T, Baritaki S and Bonavida B: Nitric oxide sensitizes tumor cells to TRAIL-induced apoptosis via inhibition of the DR5 transcription repressor Yin Yang 1. Nitric Oxide 20: 39-52, 2009.

38. Bonavida B and Baritaki S: Inhibition of epithelial-to-mesenchymal transition (EMT) in cancer by nitric oxide: Pivotal roles of nitrosylation of NF- $\mathrm{B}$, YY1 and Snail. For Immunopathol Dis Therap 3: 125-133, 2012.

39. Baritaki S, Huerta-Yepez S, Sahakyan A, Karagiannides I, Bakirtzi K, Jazirehi A and Bonavida B: Mechanisms of nitric oxide-mediated inhibition of EMT in cancer: Inhibition of the metastasis-inducer Snail and induction of the metastasis-suppressor RKIP. Cell Cycle 9: 4931-4940, 2010.

40. Girard FP, Byrne J, Downes M, Fanning D, Desgrandchamps F, Fitzpatrick JM and Watson RW: Detecting soluble clusterin in in-vitro and in-vivo models of prostate cancer. Neoplasma 57: 488-493, 2010

41. Yousfi N, Pruvot B, Lopez T, Magadoux L, Franche N, Pichon L, Salvadori F, Solary E, Garrido C, Laurens V, et al: The impact of tumor nitric oxide production on VEGFA expression and tumor growth in a zebrafish rat glioma xenograft model. PLoS One 10: e0120435, 2015.

42. Xu W, Foster BA, Richards M, Bondioli KR, Shah G and Green CC: Characterization of prostate cancer cell progression in zebrafish xenograft model. Int J Oncol 52: 252-260, 2018.

43. Livak KJ and Schmittgen TD: Analysis of relative gene expression data using real-time quantitative PCR and the 2(-Delta Delta C(T)) method. Methods 25: 402-408, 2001

44. Shiota M, Zardan A, Takeuchi A, Kumano M, Beraldi E, Naito S, Zoubeidi A and Gleave ME: Clusterin mediates TGF- $\beta$-induced epithelial-mesenchymal transition and metastasis via Twist 1 in prostate cancer cells. Cancer Res 72: 5261-5272, 2012.

45. Lourda M, Trougakos IP and Gonos ES: Development of resistance to chemotherapeutic drugs in human osteosarcoma cell lines largely depends on up-regulation of clusterin/apolipoprotein J. Int J Cancer 120: 611-622, 2007.
46. Zhang H, Kim JK, Edwards CA, Xu Z, Taichman R and Wang CY: Clusterin inhibits apoptosis by interacting with activated Bax Nat Cell Biol 7: 909-915, 2005.

47. Yasukawa T, Tokunaga E, Ota H, Sugita H, Martyn JA and Kaneki M: S-nitrosylation-dependent inactivation of Akt/protein kinase B in insulin resistance. J Biol Chem 280: 7511-7518, 2005.

48. Zhang B, Shimada Y, Kuroyanagi J, Nishimura Y, Umemoto N, Nomoto T, Shintou T, Miyazaki T and Tanaka T: Zebrafish xenotransplantation model for cancer stem-like cell study and high-throughput screening of inhibitors. Tumour Biol 35 11861-11869, 2014.

49. Kelleher ZT, Potts EN, Brahmajothi MV, Foster MW, Auten RL, Foster WM and Marshall HE: NOS2 regulation of LPS-induced airway inflammation via S-nitrosylation of NF-\{kappa\}B p65. Am J Physiol Lung Cell Mol Physiol 301: L327-L333, 2011.

50. Marshall HE and Stamler JS: Inhibition of NF-kappa B by S-nitrosylation. Biochemistry 40: 1688-1693, 2001

51. Wilson MR and Zoubeidi A: Clusterin as a therapeutic target. Expert Opin Ther Targets 21: 201-213, 2017.

52. Chun YJ: Knockdown of clusterin expression increases the in vitro sensitivity of human prostate cancer cells to paclitaxel. J Toxicol Environ Health A 77: 1443-1450, 2014.

53. García-Aranda M, Téllez T, Muñoz M and Redondo M: Clusterin inhibition mediates sensitivity to chemotherapy and radiotherapy in human cancer. Anticancer Drugs 28: 702-716, 2017.

54. Trougakos IP, So A, Jansen B, Gleave ME and Gonos ES: Silencing expression of the clusterin/apolipoprotein $\mathrm{j}$ gene in human cancer cells using small interfering RNA induces spontaneous apoptosis, reduced growth ability, and cell sensitization to genotoxic and oxidative stress. Cancer Res 64: 1834-1842, 2004.

55. Al Nakouzi N, Wang CK, Beraldi E, Jager W, Ettinger S, Fazli L, Nappi L, Bishop J, Zhang F, Chauchereau A, et al: Clusterin knockdown sensitizes prostate cancer cells to taxane by modulating mitosis. EMBO Mol Med 8: 761-778, 2016.

56. Beer TM, Hotte SJ, Saad F, Alekseev B, Matveev V, Fléchon A, Gravis G, Joly F, Chi KN, Malik Z, et al: Custirsen (OGX-011) combined with cabazitaxel and prednisone versus cabazitaxel and prednisone alone in patients with metastatic castration-resistant prostate cancer previously treated with docetaxel (AFFINITY): A randomised, open-label, international, phase 3 trial. Lancet Oncol 18: 1532-1542, 2017.

57. Chi KN, Higano CS, Blumenstein B, Ferrero JM, Reeves J, Feyerabend S, Gravis G, Merseburger AS, Stenzl A, Bergman AM, et al: Custirsen in combination with docetaxel and prednisone for patients with metastatic castration-resistant prostate cancer (SYNERGY trial): A phase 3, multicentre, open-label, randomised trial. Lancet Oncol 18: 473-485, 2017.

58. Kim N, Yoo JC, Han JY, Hwang EM, Kim YS, Jeong EY, Sun CH, Yi GS, Roh GS, Kim HJ, et al: Human nuclear clusterin mediates apoptosis by interacting with Bcl-XL through $\mathrm{C}$-terminal coiled coil domain. J Cell Physiol 227: 1157-1167, 2012.

59. Peix L, Evans IC, Pearce DR, Simpson JK, Maher TM and McAnulty RJ: Diverse functions of clusterin promote and protect against the development of pulmonary fibrosis. Sci Rep 8: 1906, 2018.

60. Bhutia SK, Das SK, Kegelman TP, Azab B, Dash R, Su ZZ, Wang XY, Rizzi F, Bettuzzi S, Lee SG, et al: mda-7/IL-24 differentially regulates soluble and nuclear clusterin in prostate cancer. J Cell Physiol 227: 1805-1813, 2012.

61. Siemens DR, Heaton JP, Adams MA, Kawakami J and Graham CH: Phase II study of nitric oxide donor for men with increasing prostate-specific antigen level after surgery or radiotherapy for prostate cancer. Urology 74: 878-883, 2009.

62. Cajigas-Du Ross CK, Martinez SR, Woods-Burnham L, Durán AM, Roy S, Basu A, Ramirez JA, Ortiz-Hernández GL, Ríos-Colón L, Chirshev E, et al: RNA sequencing reveals upregulation of a transcriptomic program associated with stemness in metastatic prostate cancer cells selected for taxane resistance. Oncotarget 9: 30363-30384, 2018.

63. Plenchette S, Romagny S, Laurens V and Bettaieb A: NO and cancer: Itinerary of a double agent. Med Sci (Paris) 32: 625-633, 2016 (In French) 